\title{
Longitudinal Stability of Person Characteristics: Intelligence and Creativity
}

\author{
D. Magnusson and G. Backteman \\ University of Stockholm
}

An empirical study based on a heterogeneous sample of approximately 1,000 boys and girls concerns longitudinal stability in intelligence and creativity data. Group-administered intelligence tests were given at ages 10,13, and 15; and different creativity tests were administered at ages 13 and 16 . The three main features of the present study were that (1) intelligence and creativity data were collected and used for the same group of individuals; (2) the individuals constituted an unselected, representative group; and (3) the data were analyzed in a multivariable-multioccasion paradigm. The requirements for construct validity proposed by Campbell and Fiske (1959) were reformulated in terms of stability over time. The two main requirements that were derived are that (1) coefficients between measurements of the same variable on different occasions must be significantly greater than zero, and (2) a stability coefficient for a certain variable must also be higher than the correlation between data for this variable at the first occasion and data for any other type of variable at the other occasion. These two requirements were fulfilled for both intelligence and creativity data in all time intervals. For intelligence measured at ages 10 and 15 , a stability coefficient of about . 75 for both boys and girls was obtained. Correlations of .45 and .42 for boys and girls, respectively, were found between measures of creativity taken at ages 13 and 16 . These results are in agreement with earlier studies of stability in intelligence and creativity, and support the construct validity of the creativity construct.

APPLIED PSYCHOLOGICAL MEASUREMENT

Vol. 2, No. 4 Fall 1978 pp. 481-490

(c) Copyright 1978 West Publishing Co.
The concept of personality consistency has been the issue of an ongoing controversy in personality research for many years (e.g., Block, 1968; Mischel, 1968). Besides lacking conceptual clarity, the debate has been hampered by a dearth of adequate empirical data interpretable in well-structured psychological models. This report is the first in a series in which an attempt is made to contribute to the empirical basis for a more fruitful discussion of the consistency issue, with emphasis on stability across time. Data were collected in a longitudinal project, which is the obvious strategy when studying stability over time (Bloom, 1964; Block, 1969; Magnusson, Dunér, \& Zetterblom, 1975).

Empirical data concerning stability of behavior should be classified with respect to two kinds of stability, (1) cross-situational stability and (2) longitudinal stability. In this context, crosssituational stability concerns rank-order stability of data for a sample of individuals for a certain variable across different situations with no, or negligible, time interval between the observation occasions. Longitudinal consistency concerns the rank-order consistency of individuals for a certain variable across time in the same situations or in different kinds of situations (Magnusson \& Endler, 1977).

This report focuses on the longitudinal rankorder stability of intelligence and creativity. Data were analyzed in a multivariable-multioc- 
casion paradigm derived from the multitraitmultimethod paradigm introduced by Campbell and Fiske (1959).

\section{Earlier Studies}

Historically, the best empirical evidence for the stability of psychological mediating variables emanates from the research on abilities, especially intelligence (Anastasi, 1968; Bloom, 1964; Hunt, 1961; Mischel, 1968). Bloom (1964) refers to five different longitudinal studies which have followed groups of children from approximately 5 to 21 years of age with different tests of intelligence. The reports by Honzik, MacFarlane, and Allen (the California Guidance Study; 1948) and Bayley (Berkeley Growth Study; 1949) listed in Table 1 are examples of the longitudinal studies referred to by Bloom. However, the samples in these studies are small and restricted compared to those used by Husén (1950), Härnqvist (1968), and Hopkins and Bracht (1975), which contain 613 and 4,616 male students and 927 boys and girls, respectively.

The stability coefficients for different intervals of time, shown in Table 1, display a considerable stability for intelligence. As pointed out by Mischel (1968), other mediating variables which are "strongly correlated with intelligence often also are fairly consistent." High stability over time in scholastic achievement has been reported. Moss and Kagan (1961) found correlations of .38 to .68 for achievement between ages 6-10 and adulthood. Another example of stability in achievement data is reported by Magnusson (1977), who obtained correlations around .50 in relative achievement data for the age intervals 10 to 13 and 13 to 16 .

The stability of creativity has been studied almost invariably as short-term stability. An exception is a five-year test-retest study (Cropley \& Clapson, 1971), which yielded correlations of about .45 (corrected for restriction of range) on two tests of creativity (Consequences and Circles). That study concerned a selected group of individuals from the age of 12 to the age of 17. There seems to be a strong case for investigating stability in creativity data on an unselected, representative group.

\section{Purpose}

The present study concerns the longitudinal stability of intelligence and creativity. It differs

Table 1

Correlations Between General Intelligence at Approximately 10 and 18 Years of Age in Different Longitudinal Data

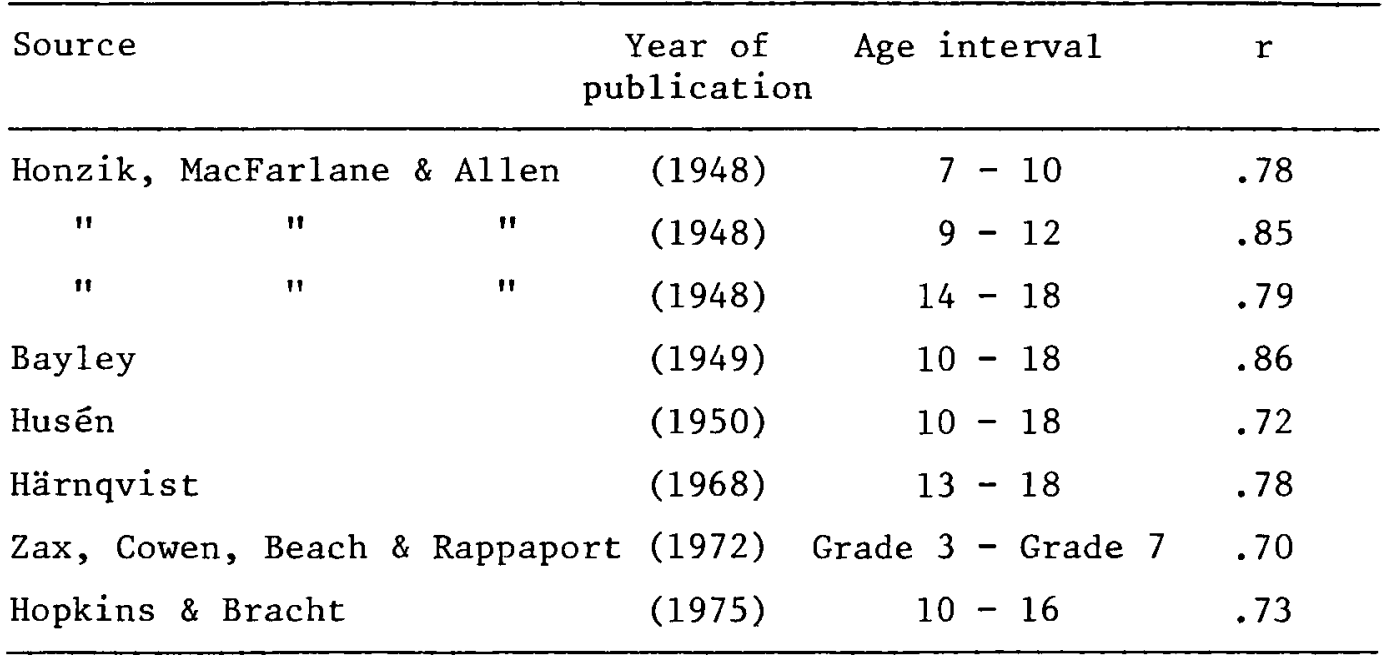


from earlier studies by combining three characteristics: (1) intelligence and creativity data were collected for the same group of individuals; (2) the individuals constituted an unselected representative group; and (3) the data for intelligence and creativity were analyzed in a multivariablemultioccasion paradigm.

\section{METHOD}

\section{Subjects}

The present study is based on data collected for the Örebro project (Magnusson, Dunér, \& Zetterblom, 1975), which is a longitudinal research program directed toward the individual development and adjustment of two cohorts of Örebro children-one cohort born in 1952 and the other, in 1955. Each group comprises about 1,000 boys and girls. The pupils born in 1952 have served as a pilot group and those born in 1955 constitute the main group. The population of the main group is defined as all school children in the Swedish town of Örebro who in 1965 were about 10 years old and in Grade 3 in the public high school. The town of Örebro is taken to represent a typical Swedish town with a diversified industry and a well-developed school system. Migration from Örebro is comparatively small, and the drop out in the long-term followup of the main group is relatively limited, about $18 \%$ from 9 to 16 years of age. The effect of the drop out on the dispersion of the data is negligible. Partial drop out for some types of data was due to unavoidable factors, e.g., temporary illness. The present study makes use of data from ages 10 to 16 . The sample consists of 380 boys and $\mathbf{4 0 8}$ girls for whom such data were available.

\section{Variables}

\section{Intelligence}

Ages 10 and 13. Six ability group tests from the DBA test battery, a multifactor test (Härnqvist, 1962), were given to the subjects in Grade 3, when they were 10 years old, and in
Grade 6, when they were 13. Synonyms (Sy) and Opposites $(\mathrm{Op})$ are both taken to measure verbal comprehension. Letter groups (Le) and Figure sequences $(\mathrm{Fi})$ contain abstract logical tasks and are considered to measure a logical-inductive ability. The last two subtests, Cube counting ( $\mathrm{Cu}$ ) and Metal folding (Me), consist of spatial tasks. The reported split-half reliabilities for Sy, $\mathrm{Op}$, Le, Fi, $\mathrm{Cu}$, and $\mathrm{Me}$ ranged between .85 and .90 ; and the calculated reliability of the total test was about .95 .

Age 15. In Grade 8, when the students were 15 years old, the multi-factor test WIT III (Westrin, 1969) was used to measure general intelligence. This test is likewise a factor type test and contains four subtests: (1) Analogies (WITAn), taken to measure an inductive verbal factor; (2) Opposites (WITOp), a test of verbal comprehension; (3) Number combinations (WITNu), considered to measure a logical-deduction ability; and (4) Puzzle (WITPu), a test of spatial ability. For the present age, the reported split-half reliability for the total test was approximately .93.

\section{Creativity Ability}

Age 13. Creativity was measured in Grade 6 with two tests, Consequences and Divergent figures (Larsson \& Sandgren, 1968). Consequences (Con; What would happen, if . . . .) is a verbal test closely related to Guilford's (1967) Divergent Semantic Unit. Divergent figures (DF) is a type of test called "doodles" (Larsson \& Sandgren, 1968) and consists of a visual stimulus material; it has an equivalent in Wallach and Kogan's (1965) "Pattern meanings." In Guilford's group of divergent production tests, DF represents Divergent Figural Implications. The reliability of the total scores on the creativity tests in Grade 6, at 13 years of age, was about .92 .

Age 16. When the pupils were 16 years old, creativity was measured by three tests-Brick Uses, Plot Titles, and Purdue Creativity Test. Brick Uses (BU) and Plot Titles (PT) are Swedish versions of Guilford's original divergent 
thinking tests. PT is focused on verbal divergent production. According to Guilford, both BU and PT are classified as Divergent Production of Semantic Units. The reliabilities reported on Swedish samples for BU ranged from .61 to .84 ; and for PT, .92 (split-half). The third test was a reduced version of the Purdue Creativity Test (PC) originally designed by Lawshe and Harris (1960). PC is based on Guilford's theoretical formulations, and the original test is considered to measure Divergent Figural Units. Originally designed for selection and placement of engineering personnel, the test has been shown to do well in other applications (Ekvall \& Holmqvist, 1971). Reported split-half reliabilities range from .87 to .95 (Ekvall \& Holmqvist, 1971). Törner (1969) has adapted this test to Swedish and reports a reliability for a group of engineers of .92 (split-half corrected coefficient). All of the creativity tests used have been scored according to fluency.

\section{Procedure}

The correlation method gives the most appropriate statistic for describing longitudinal consistency when one is mainly interested in measuring relative consistency or rank-order stability of variables for samples of individuals. A correlation matrix containing coefficients for stability of a set of variables can be characterized as a multivariable-multioccasion matrix, comparable to a multitrait-multimethod matrix. Starting from a multitrait-multimethod matrix, Campbell and Fiske (1959) proposed four requirements for a completely satisfactory validation of a certain variable:

1. The coefficents of correlation between measurements of the same variable with different methods must be significantly greater than zero.

2. The measurements of a variable must correlate more closely with measurements of the same variable which are measured with another method than with measurements of another variable which are measured with the same method.

3. A validity coefficient for a given variable should be higher than the correlation between the measurements of this variable and the measurements of all other variables with any other method.

4. Whether the same or different methods are used, the magnitude of the coefficients for the correlation between different variables should have the same pattern.

If the first requirement is fulfilled, there is evidence for convergent validity. If Requirements 2,3 , and 4 are complied with, there is evidence for discriminant validity.

These requirements can be formulated in terms of stability. Then the requirements of rank-order consistency of data for a certain variable across methods are replaced by requirements of rank-order consistency in data for a certain variable across time, as follows:

1. The coefficient of correlation between data for the same variable on different occasions must be significantly greater than zero.

2. Data for the variable under consideration must correlate higher with data for the same variable which are collected on another occasion than with data for another type of variable which are collected on the same occasion.

3. A stability coefficient for a given variable should be higher than the correlation between data for that variable at the first occasion and data for every other type of variable at the other occasion.

The fourth criterion formulated by Campbell and Fiske-that the magnitude of the correlations should have the same patterns across methods-is not appropriate for the study of stability. A given person characteristic can be totally stable, while the total patterns of behavior for individuals change over time. This circumstance makes Requirement 2 dubious, too. The 
strong and necessary requirements for rankorder stability, therefore, are Requirements 1 and 3.

\section{Correction for Attenuation}

In studying personality over time (i.e., stability of person characteristics), what is of primary interest is the stability of individual true scores for the variables studied. The stability coefficients calculated on raw data will underestimate the stability of true scores because of deficient reliability of the measuring instrument. In order to correct for measurement error and estimate the stability of true scores, the obtained stability coefficients have been corrected for attenuation (see Magnusson, 1967, p. 148). It should be observed that the stability coefficients for true scores are only estimates. The correctness of the estimated coefficients is dependent on the relevance and correctness of reliability coefficients used in the correction formula, as well as on the appropriateness of the classical measurement model (see Magnusson, 1976). The corrected coefficients are shown within parentheses in Table 3.

\section{RESULTS}

The total multivariable-multioccasion matrix is reported in Table 2. Coefficients are reported for factors and total scores.

\section{Stability in Intelligence Data}

Requirement 1 . The stability coefficients for intelligence factor scores across different intervals are presented in the diagonal (underlined) of the heterovariable-heterooccasion blocks. The uncorrected and corrected stability coefficients for intelligence are presented in Table 3. The stability coefficients were all highly significant for all factors and for the total intelligence score. Thus, these results confirm earlier findings.
Intelligence data were obtained by one test (DBA) for ages 10 and 13 and by another test (WIT) for age 15. These two tests consist of different subtests which can be grouped with respect to three intelligence factors - a verbal, a logical, and a spatial factor. However, assignment of a subtest to a certain factor is not always quite clear, an obvious example being Analogies in WIT, which is supposed to measure an inductive, verbal factor. This is expressed in high intercorrelations with both the verbal comprehension subtests in WIT and the inductive subtests in DBA. Different methods for studying the factor at different levels mean, of course, that one introduces some irrelevant method variance which should be considered error variance in some of the stability coefficients for the intervals that include age 15 .

The figures in Table 3 reveal two systematic patterns which should be commented on. First, all coefficients for stability of factor scores were lower for girls than for boys. Second, there was a systematic difference between factors in the stability coefficients. For all intervals the stability coefficients were highest for the verbal factor, next highest for the spatial factor, and lowest for the logical factor. To some extent the low stability for the logical factor might be explained by the circumstance described above, that some tests are not pure in their factor belongingness. However, the same differences in stability between factors also exist for the interval 10 to 13 years, where the same tests were used on both occasions. For that interval, the common variance for the logical factor was $43.4 \%$ for boys and $39.6 \%$ for the girls, while for the verbal factor it was $67.1 \%$ and $62.9 \%$, respectively.

Requirement 2 . At the total score level, Requirement 2 was met for total intelligence scores in relation to creativity total scores for all intervals and for both sexes. At the factor level, Requirement 2 was met for all intervals and for both sexes for the verbal and the spatial factors. For the logical factor, however, it was not met for the age intervals 10 to 15 and 13 to 15 . For both boys and girls the correlations between the 


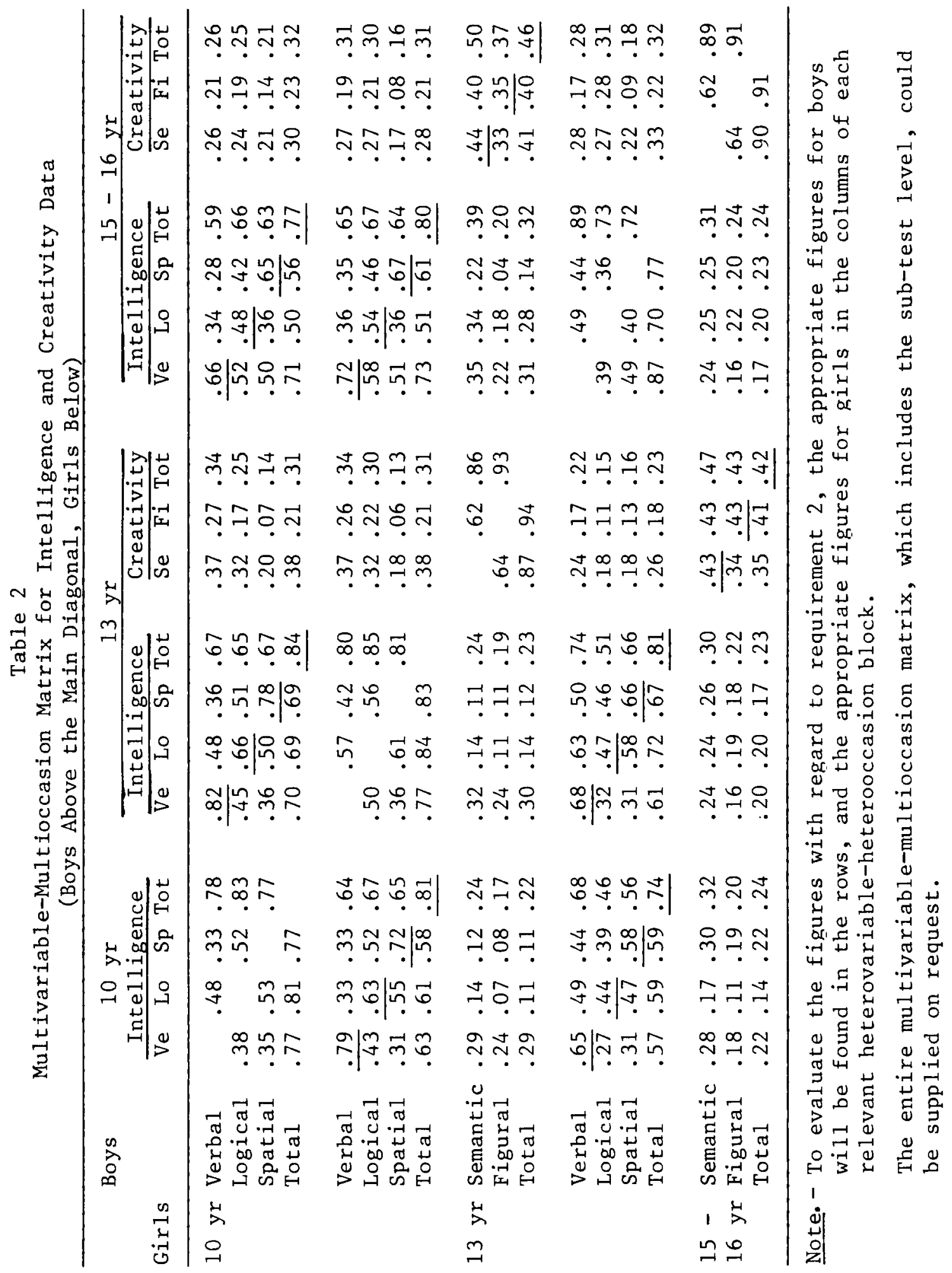




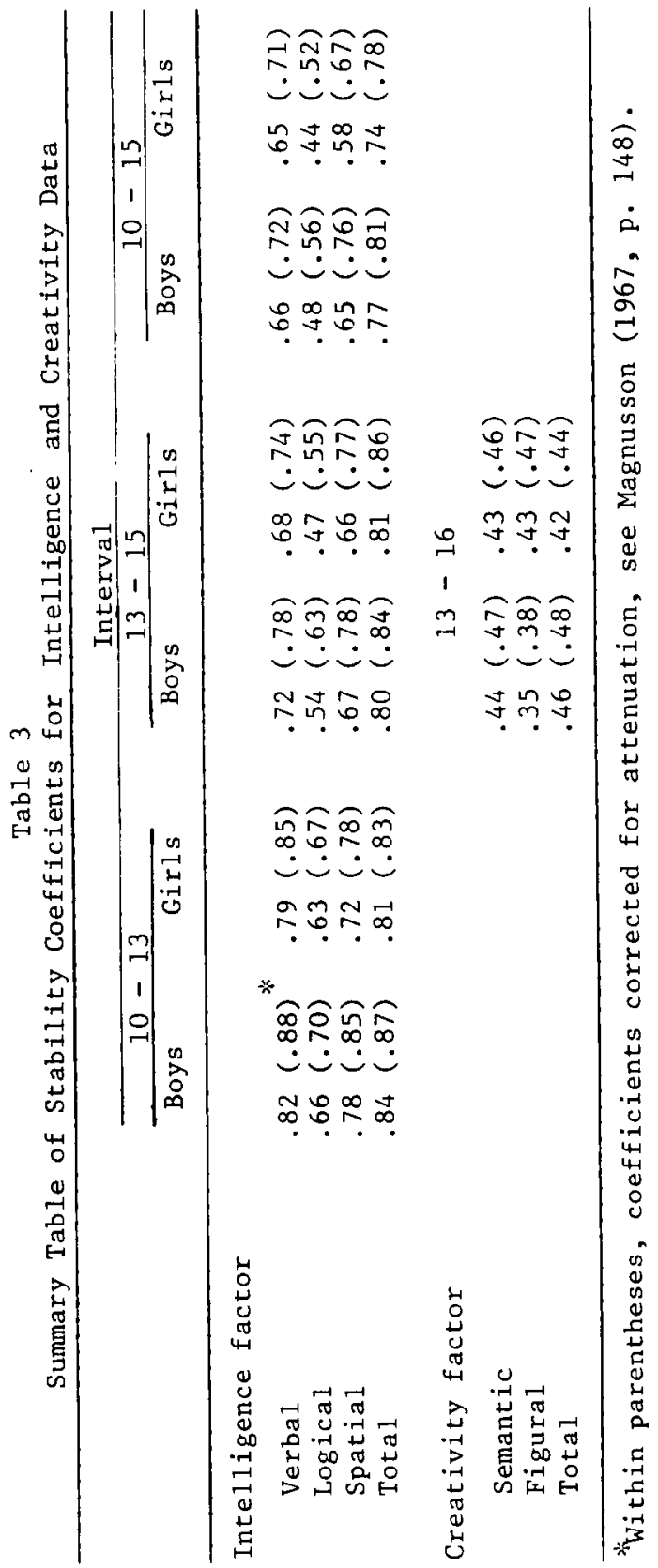

logical and the spatial factor on the first occasion of the interval were higher than the stability coefficient for the logical factor (see heterovariable-monooccasion blocks in Table 2). The correlations were .52 for boys and .53 for girls at the age of 10 , and .56 for boys and .61 for girls at the age of 13 . The correlation between the logical and the verbal factor was .50 for girls at the age of 13 , which exceeded the stability coefficient for the age interval 13 to 15 .

It should be observed that the logical factor met Requirement 2 for the interval 10 to 13 . The deficiencies in meeting the requirement are valid for the intervals when the factors were measured by partly different tests, with the consequences discussed above.

Requirement 3. The stability coefficients for total intelligence scores were consistently higher than the coefficients between intelligence scores and creativity scores for the same interval. All the factors met Requirement 3 with no exceptions. All stability coefficients for factors were higher than any coefficients for the correlation between a factor and any other factor for the same interval.

Conclusion. Both the crucial requirements for stability (Requirements 1 and 3 ) were met in data for intelligence factors.

\section{Stability in Creativity Data}

Creativity was measured by two tests at the age of 13 and by three other tests at the age of 16. Since different tests were used on the two occasions, some irrelevant method variance was introduced which will act as error variance and influence the stability coefficients. The tests at the two ages were chosen on the basis of psychological theory to cover two creativity factors. However, the intercorrelations between the subtests were already high on the first occasion and about the same size, independent of assumed factor belongingness. Thus, it seems inadequate to discuss them as measuring different factors (see discussion above and the heterovariablemonooccasion blocks in Table 2). The present 
account therefore deals with the stability of creativity as a single main factor.

From Table 2 it should be especially noted that the intercorrelations between creativity and intelligence were low for each of the two ages and considerably lower than the intercorrelations between different types of creativity data. Tables 2 and 3 present the correlations between creativity data from the ages of $\mathbf{1 3}$ and 16 .

Requirement 1 . The stability coefficients for creativity presented in Table 3 are statistically significant and surprisingly high, considering (1) that rather different types of tests were used at the two ages and (2) that the coefficients were not corrected for attenuation. For the total creativity scores, the stability coefficients were .46 for boys and .42 for girls.

Requirement 2 . The stability coefficients covering three years were clearly higher for creativity scores than the correlations at any age level studied between creativity and any of the intelligence factors.

Requirement 3. The stability coefficients for creativity were clearly higher than the coefficients for the correlation between creativity data at the age of 13 and data for any intelligence factor at the age of 16 .

Conclusion. Total creativity scores (creativity regarded as a single factor) met the main criteria for stability. The stability coefficients were significant and higher than the correlations between creativity data and intelligence data on each specific occasion, and higher than the coefficients for the correlation between creativity data and intelligence data for any specific time interval. This result should be evaluated against the background that creativity was measured by different tests at the two age levels. It should be added that the creativity responses were scored according to fluency, which may have introduced irrelevant variance in the data. The results also support the construct validity of the creativity construct.

Getzels and Jackson (1962) and Torrance (1960) suggested that there is little relationship between creative thinking and the generalized ability measured by intelligence tests. Ripple and May (1962) criticized the aformentioned investigators because of their homogeneous sample and pointed out that the relationship between measures is partially a function of the groups studied. In the present study the sample used was heterogeneous and, on the whole, representative of the age group.

\section{DISCUSSION}

The analyses of the stability of intelligence and creativity data in the multivariable-multioccasion paradigm imply that stability is investigated, not only be studying single stability coefficients, but also by looking at the consistent patterns of intercorrelations across time for a set of different variables, one of which is the variable under consideration.

The overall results for both intelligence and creativity data showed high stability of rank orders over the period from 10 to 16 years of age, though this stage is characterized by large interindividual differences with respect to the rate of development of different aspects of personality. The results are compatible with the conclusions drawn by reviewers of the literature on personality consistency (e.g., Magnusson, 1976), who argue that such variables as intelligence and creativity (which cover the structural characteristics of an individual's mediating system by which he/she selects, treats, and transforms information) should be highly stable.

The stability coefficients for intelligence were considerably higher than those for creativity. One reason for this result has already been discussed, namely that creativity was measured with instruments of clearly different character at the two ages. For example, at one age the instruction required the students to interpret geometric figures, while at the other, the students were required to suggest a headline for an article. Obviously, such differences in the type and content of methods for data collection will lead to different contents of the aspects of creativity that are actually measured. That instruments varying so much in character were used reflects 
the circumstances that (1) theoretical and empirical analyses are less developed in the field of creativity than in the field of intelligence and (2) there is a lack of good methods for measuring different aspects of creativity.

\section{References}

Anastasi, A. Psychological testing. New York: Macmillan, 1968.

Bayley, N. Consistency and variability in the growth of intelligence from birth to eighteen years. The Journal of Genetic Psychology, 1949, 75, 165-196.

Block, J. Some reasons for the apparent inconsistency of personality. Psychological Bulletin, 1968, 70, 210-212.

Block, J. Lives through time. Berkeley, CA: Bancroft Books, 1969.

Bloom, B. S. Stability and change in human characteristics. New York: Wiley, 1964.

Campbell, D. T., \& Fiske, D. W. Convergent and discriminant validation by the multitrait-multimethod matrix. Psychological Bulletin, 1959, 56, 81-105.

Cropley, A. J., \& Clapson, L. Long term test-retest reliability of creativity tests. British Journal of Educational Psychology, 1971, 41, 206-209.

Ekvall, G., \& Holmqvist, R. [Prediction of Creativity Behavior. Test Manual.] Prediktion av kreativit beteende. Undersökningsmanual. Malmö: Swedish Council for Personnel Administration, 1971.

Getzels, J. W., \& Jackson, P. W. Creativity and intelligence. New York: Wiley, 1962.

Guilford, J. P. The nature of human intelligence. New York: McGraw-Hill, 1967.

Honzik, M. P., MacFarlane, J. W., \& Allen, L. The stability of mental test performance between two and eighteen years. Journal of Experimental Education, 1948, 17, 309-324.

Hopkins, D. K., \& Bracht, G. Ten-year stability of verbal and nonverbal IQ scores. American Educational Research Journal, 1975, 12, 469-477.

Hunt, J. McV. Intelligence and experience. New York: The Ronald Press Company, 1961.

Husén, T. [The predictive value of group intelligence test scores.] Testresultatens Prognosvärde. Stockholm: Gebers, 1950.

Härnquist, K. [Manual for DBA.] Manual till DBA. Stockholm: Skandinaviska Testförlaget, 1962.

Härnqvist, K. Relative changes in intelligence from 13 to 18. II. Scandinavian Journal of Psychology, $1968,9,65-82$.

Larsson, L., \& Sandgren, B. [A report on the develop- ment of creativity between grade 4-9 and an investigation of the covariation between creativity and intelligence.] En studie av kreativitetsutvecklingen inom àrskurserna 4-9 samt en undersökning av kreativitetens samvariation med intelligensen. Unpublished manuscript, University of Gothenburg, Department of Psychology, 1968.

Lawshe, C. H., \& Harris, D. M. Purdue Personnel Test. Manual of instructions to accompany Purdue Creativity Test, Forms $G$ and $H$. Purdue: Purdue Research Foundation, 1960.

Magnusson, D. Test theory. Reading, MA: AddisonWesley, 1967.

Magnusson, D. The person and the situation in an interactional model of behavior. Scandinavian Journal of Pyschology, 1976, 17, 253-271.

Magnusson, D. Overachievement as a person characteristic and its relation to physiological reactions, or what does it cost to try to achieve too much? (Report No. 493) University of Stockholm, Department of Psychology, 1977.

Magnusson, D., Dunér, A., \& Zetterblom, G. Adjustment: A Longitudinal Study. Stockholm: Almqvist \& Wiksell, 1975. (New York: Wiley, 1975.)

Magnusson, D., \& Endler N. S. Personality at the crossroads: Current Issues in interactional psychology. Hillsdale, NJ: Lawrence Erlbaum Associates, 1977.

Mischel, W. Personality and assessment. New York: Wiley, 1968.

Moss, H. A., \& Kagan, J. Stability of achievement and recognition seeking behaviors from early childhood through adulthood. Journal of Abnormal and Social Psychology, 1961, 62, 504-513.

Ripple, R. E., \& May, F. B. Caution in comparing creativity and IQ. Psychological Reports, 1962, 10, 229-230.

Torrance, E. P. Explorations in creative thinking. Education, 1960, 81, 216-220.

Törner, G. [Purdue Creativity Test. A Swedish Version of an American Technical Creativity Test.] Purdue kreativitetstest. En svensk bearbetning av ett amerikanskt tekniskt kreativitetstest. Lund: University of Lund, Department of Psychology, 1969.

Wallach, M. A., \& Kogan, N. A. A new look at the creativity-intelligence distinction. Journal of Personality, 1965, 33, 348-369.

Westrin, P. A. [WIT III Manual.] WIT III Manual. Stockholm: Skandinaviska Testförlaget, 1969.

Zax, M., Cowen, E. L., Beach, D. R., \& Rappaport, J. Longitudinal relationships among aptitude, achievement and adjustment measures of school children. The Journal of Genetic Psychology, $1972,121,145-154$. 


\section{Acknowledgments}

The study was supported by a grant from the Swedish National Defence Research Institute to D. Magnusson. The study is part of a program on longitudinal stability of person factors.

\section{Author's Address}

David Magnusson, Department of Psychology, University of Stockholm, Box 6706, S-113 85 Stockholm, Sweden. 